\title{
Educational System and Development in Ethiopia: For Public Empathetic of Sustainability
}

\author{
Jember Solomon Tadele \\ Institute of International and Comparative Education, Beijing Normal University, Beijing, China
}

Email address:

Solomontadele7@gmail.com

\section{To cite this article:}

Jember Solomon Tadele. Educational System and Development in Ethiopia: For Public Empathetic of Sustainability. Education Journal. Vol. 10, No. 3, 2021, pp. 91-97. doi: 10.11648/j.edu.20211003.14

Received: February 23, 2021; Accepted: June 2, 2021; Published: June 10, 2021

\begin{abstract}
The ideas of 'sustainable development' and 'sustainability' have been endorsed to report worldwide public, economic and environmental tasks, together with insistent forms of absolute poverty and various forms of social and economic inequality (UNESCO, 2009b). Education is important so as to develop the opportunities and autonomies of all people. Education for Sustainable Development (ESD) is a forceful idea that integrates a new vision of education that discoveries to give power for the people of all years to assume the accountability for creating, innovating and enjoying a sustainable future. The study was focused on investigating the Education for Sustainable Development in the Ethiopian context. The methodology of the study was document analysis. The documents were a selection of currently published scholarly papers in peer-reviewed journals addressing. Ethiopian education system had left the rich literary heritage such as the alphabet and useful resources. And the current Ethiopian education arrangement was suffering from complicated problems. The main problems were related to the issues of relevance, quality, equity, and access. And it is criticized because of many factors that are lack of conducive environment and large classroom size. That plays a pivotal role in quality education in Ethiopia. Within the framework specified in the Education and Training Policy and Strategy (ETPS), the state calculated the Education Sector Development Program (ESDP), which is a long range-rolling Design with a focus on the comprehensive improvement of education over a twenty-year period.
\end{abstract}

Keywords: Sustainable Development, Education, Ethiopia, Modern Educational System, Development

\section{Introduction}

Ethiopia is one of the oldest country in the world. Which is found Horn of Africa; it is accredited as being the origin of mankind and is the second greatest crowded country in SubSaharan Africa next to Nigeria. Ethiopia is under a system of decentralized government administration diverse people with varying languages, religions, value, traditions and custom.

At the early stage, Ethiopian educational system is in expansion, its financing supplies can be predictable to produce as the nation struggles to universalize primary school conclusion and foster the development of other levels and types of education and training. UNESCO is doing a lot of activities that related to this goals to recover the access of quality education on sustainable development at all levels and in all social contexts, to transform society by reorienting education and help people to progress knowledge, skills, values and behaviors' needed for sustainable development

\section{$[12,16]$.}

The description of the history of Ethiopian education in this paper may not be very important, However; it gives brief background information to the development of limprovement $\checkmark$ of education in the Ethiopian context. Education has a crucial role in the different aspect of development $[3,13]$. It is one of an important right, and also one of the most authoritative tools for sustainable development. Investing in quality education for every child, youth and adult are essential - not only had to achieve the education-related goals and targets, but to understand the other sustainable development goals and objectives [6].

The study was focused on investigating the Education for Sustainable Development in the Ethiopian context. The methodology of the study was document analysis. The documents were a choice of newly published scholarly papers in peer-reviewed journals addressing.

In the contemporary time, children and the majority of 
adults in the century side of Ethiopia have low access to get modern education so; I can say that indigenous education is playing a great role the rural part of Ethiopia. In addition to this, it has an important role in preparing the young generation for their future societal role. Education is a vital and high-return deal in every aspect of growth. But it was not largely practiced in the country [12].

According to [6] in the Ethiopian context, Education is not new because education is the home of an ancient civilization. Since the arrival of the Orthodox Church in Ethiopia in the 4th A.D, it includes writing is the part of its curriculum. Religious education has been agreed by the Church, although to a sectional of the population, as a result of which the country has ordered as the only Sub-Saharan nations with its own indigenous system of writing.

According to $[22,26]$ Ethiopian church education had left the rich literary heritage such as the alphabet and useful resources. The Ethiopian church education had two conflict phenomena's that are; almost all modern writes and many musicians are the outcomes of it. On the other hand, the church was the greatest resistance to the development of modern education.

And the other component of education in Ethiopia was the encouragement of Islam religion $[6,22]$. Arab culture and faith were adopted in much of the southern and South-eastern part of Ethiopia. The educational process was non-formal. Non-formal education in the school system was established to teach the moral, integrity and theology of Islam religion. Designed to impart skills and knowledge within the religious realm, the Islamic education system accentuated reading and reading in Arabic.

Generally, religious education was the basis of modern education in Ethiopia. It gives a lot of teachers, judges, poem writers, book writers, language teachers, governors, businessman, scribes, treasures, general administrators, diplomats, and educators. [22]

\section{Methodology}

This paper is based on data which is found from different documents. Document analysis is a way of gathering data by reviewing current documents. Document examination is a form of qualitative investigation in which documents are understood by the investigator to give voice and meaning around an assessment topic [36, 37]. This research is tried to investigate that education for sustainable development in the Ethiopian background. The documents review is chosen that is related to the feasibility of the topic. The researcher has conducted this research to understand the situation of Ethiopia that related to education for sustainable development. It inspects a collection of newly published scholarly journals in peer-reviewed papers addressing education for sustainable development subjects and matters.

\section{Modern Education in Ethiopia}

At the period Emperor Menelik the modern education was introduced. The introduction was taking a long way to persuade the traditional Ethiopian society $[22,27]$ Ethiopian history, the first modern school was opened in 1908 by Menelik II, the school for accepted hundred children of the aristocracy.

The objective of this school is cultivating the young to certify peace and reconstructing the country and allowing to occur as a great nation $[22,28]$. It also had another objective for producing administrators, interpreters, and technicians to build sustainable external relations capacity specifically with the western countries [10, 14]. In the same token [3] when Emperor Menelik II came to power in 1889; He wanted the expansion of education in order to modernize Ethiopia, but the practice was not satisfied.

The establishing of central state ability and perpetual urban seat of authority, the coming of foreign embassies, and the development of modern economic sector were some of the objective conditions that called for contemporary education in Ethiopia. At end of 19th-century young Ethiopian students are sending abroad for higher education.

The young Ethiopian who was sent involved by the religious organizations was predictable to spear the faith upon their arrival to the country. On the other way, Emperor Menelik had a very strong wish to develop a strong government in the country. Thus having educated of the compensations of contemporary education, those from young Ethiopians, who were sent to abroad, Menelik decided to send a lot of numbers different European countries. The Ethiopian students who sent to aboard by the government were qualified in military science, agriculture, engineering and other parallel professions [10, 14, 24]. Those skilled Ethiopian students were not contributed by their fields, rather participated in political potions or governmental leaders.

Following the change in social values, faith, and philosophy, the educational infrastructure was also changed drastically. The organizational structure of educational activities was changed based on the objectives of the communist government. In the National Democratic Revolution Program of the Ethiopian Government $[1,6,16]$

According to $[6,18,27]$, the system of education in the Derg regime was partial by some influences. Those features are involved that durable resolve and assurance of the Derg regime for expanding of communist ideology. In addition to that, it includes the development of curriculum, based on the philosophy of European educational structure or system. As the result, as all education system was aimed to focus on communist ideology. It was voiced through the National Democratic Revolution in 1976, General Directives of Ethiopian education in 1980, and the guidelines of the Working Party of Ethiopia in 1984 [2, 7] Socialist education stressed the inculcation of ideology as a major objective with Marxism and the value of making as the main pillars [10].

According to [6] by 1959/60, student enrollment had increased to 0.25 million. And he continues his criticisms were directed in the educational system. So he lists the following: a) Educational prospects were a few; b) the expansion of education was prejudiced; c) The curriculum 
was more academic than technically-oriented; d) The attrition rate was high; e) The curriculum scarcely reproduced the requests and difficulties of the country; f) The educational arrangement was so central at the leadership and administrative levels that it became victim to bureaucratic shackles.

\section{Current Education Arrangement}

Current Ethiopian education arrangement was suffering from multifaceted problems. The main difficulties that related to the matters of significance, quality, equity, and access. The Ethiopian Federal Democratic Republic constitution has declared that related to education, it is one of the fundamental human rights, thus. It is permitted from any political and religious ideology. In the structure the matters of education and human right, every nation and nationality has the right to learn by its own language, at least there straightforward and over-all education in primary level.

According to the composition of the $[13,16,17]$ the Ethiopian government shall have the duty to support on the basis of equality the growth and enrichment of cultures and traditions that are compatible with fundamental rights democratic norms and ideas, and the provision of constitutions. Besides, the Education and Training Policy of Ethiopia [13] states" ... to provide education that promotes democratic culture, tolerance and peaceful resolutions of differences and that raises the sense of discharging societal responsibility." Similarly, the Transitional Government of [16] publicized that as education "plays a role in the promotion of respect for human rights and democratic values, creating the condition for equality, mutual understanding, and cooperation among people. These imply that education is a base for life. Similarly, the new culture policy also states that education should develop the culture of all ethnic groups in the country by integrating them into the school curriculum. The policy more suggests the development of shared common for mutual understanding on the basis of equal development for all ethnic groups' and cultures of the country [13]. In the twentieth century, education in Ethiopia was access to scant, and if it existed at all, it was unequal and skewed in favor of urban and affluent families. Such an educational landscape indicates that there had been of inequality of occasion in the sector for decades [4, 19].

The education and training policy predicts bringing-up citizen capable through a human viewpoint, general accountability, and democratic value, having established the essential productive, resourceful and appreciating capability, in order to contribute productively in growth and the employment of properties and the environment at great. Education does not function in separation; rather it has to be joined with investigation, practice, and growth to recompense concerning an all-rounded growth of society [8, 10] Education that doesn't address the social request of society and helps countries to grow the capability to decide social and individual difficulties; that doesn't allow the new generation to reproduce their own style of life by captivating good involvements from the past and discover their own has no value.

As to [6] the current educational system is criticized because of many factors that are lack of favorable environment and large classroom size. That plays an essential part in quality education in Ethiopia. Within the framework stated in the Education and Training Policy and Strategy (ETPS), the government calculated the Education Sector Development Program (ESDP), which is a long range-rolling Strategy with an emphasis on the inclusive expansion of education over a twenty-year period.

\section{The Significant of Developments}

Development; economic growth by itself is not development: the way the economy is organized and the productivity of economic activity is also very important of development. Development theories have to be concerned with economic development, even if not with economic development alone [7]. Development is the goal of every individual, group and nation. It makes a better life for every people. Every nation strives for development.

Growth is not morally an economic spectacle. In addition to the enhancements in proceeds and output, it typically includes very fundamental changes in institutional or organizational, social, administrative structures, popular attitudes and, in even duties and principles. 'Development' is an idea which is focused on both theoretically and politically, and it is characteristically both multifaceted and unclear. Currently, it has occupied on the incomplete import of the preparation of growth activities, particularly in pointing at reducing deficiency and the Millennium Development Goals [22, 29].

Education is significant in instruction to increase the opportunities and autonomies of all people. Education may aid growth the human capability, opportunities, and independences necessary to grow a nation. Education is one way that allows for improved health, more job occasions and novelty to propel the economy [10,28].

It is known that Education has an important inventor of growth at the individual, community, nationwide and worldwide levels. For individuals' level, education is a lifetime advantage and one of the most economically complete savings of an individual can [4]. Education not only carefully relays to other subdivisions but also inspirations them to advance opportunities and freedoms [8, 31-33].

\section{Education for Sustainable Development}

Rendering to $[10,12]$. Education for sustainable development is about applied and contextualized education in how to live an improved life and to maintenance for the contemporary and upcoming of the globe. Human resources growth establishes the groundwork upon which quantifiable growth can happen, and education characterizes the main 
form of human resources expansion. Besides that, it is largely supposed that the development of educational occasions is an underpinning to the nation's augmented socio-economic enlargement. Education gives an important and base for all human development and its availability and quality are governing to the human source growth of any society. The main objective of spreading a basic level of education to all about the glob has taken the imaginings of all nations. And it was a main consequence of all over the world. World Conference on Education for All, held at Jomtien in 1990, and it was reconfirmed in a sequences of conferences through the resulting decade $[7,12]$.

Education for Sustainable Development (ESD) is a dynamic concept that includes a new vision of education that finds to give power to all ages of people. It is to assume that have its own accountability for innovating and appreciating a sustainable development for the future. The general aim of education for sustainable development is to allow citizens to act or doing for encouraging environmental and social modification, suggesting a participating and action-oriented method [7, 10]. Education for sustainable development is integrated concepts and analytical tools from different disciplines or subject area to benefit people for more understand of the world they animate [21, 28]

Following sustainable expansion concluded education needs instructors and beginners to reproduce disapprovingly on their own societies; recognize non-viable fundamentals in their lives, and discover pressures among contradictory standards and areas. Education for sustainable development conveys new inspiration for erudition as pupils become authorized to grow and assess another visions of a sustainable upcoming and to work to together with accomplish these visions.

According to $[29,33]$ is spearheading the U.N. effort of that to tool Education for sustainable growth in a worldwide. The goal is "to integrate the values inherent in sustainable development into all aspects of learning to encourage changes in behavior that allow for a more sustainable and just society for all".

Education for sustainable development emphasizes that the improvement of citizens and agents who have knowledge, skills, and values that upkeep supportable performance, civic appointment, as well as practical employ and a improved or greatest quality of life $[4,15,32,33]$. The dominant approach this point is making pupils for all-time learning, and an adaptive quality, it scripts the recruit suppler in a time when most societies are feeling affected social, environmental, and economic transformation.

There is a strong commitment in education for sustainable development to moving arrogances and performs so that movements are more reliable with sustainability in whatsoever intelligence this period may be nearby built. Education for sustainable development is a paradigm change in education which energies elsewhere the old-style kingdoms of education $[10,15,28]$. Education for sustainable development is about applied and contextualized knowledge in how to living an improved lifetime and to upkeep for the current and upcoming of the in the world.

However, the influence between education and development that works in the other direction as well. The unsustainability of development may have an impact on schooling, and thereby on individual development [16, 28]. In Ethiopia dropout and failure rates are alarming; many leave semi-literate, soon to relapse into illiteracy. Given that the result of such failure is often an exclusion from social processes, such as poor quality education, education coverage etc... are part of a vicious circle of unsustainability.

\section{Development Theory and Desirable Change}

Development theory is a collection of different theories about how desirable change in different society is best achieved. Those theories come from a variety of social science disciplines and approaches. So in this contextual sustainable development is a progress that encounters the requirements of the contemporary deprived of cooperating with the capability of upcoming peers to meet their own requirements [10, 31]. In any effort at development theory structure - which afterward an early academic strength, springs way to an inductive searching into the facts of development procedures and involvements, and thereby continually involves in sanitizing theoretical preparations [5, 23]

So very intensely deep-seated are such expectations, in our present theoretical knowledge, that neither our academic assessments nor even our field investigation results and intelligences have been able to construct satisfactory lines in contradiction of them. And despite our dissatisfaction with the state of development studies and the periodic selfcriticism of our own methods, we almost always seem to go back to responsibility what we did previously.

Additionally, the method in which our societal science familiarity has advanced, mainly by cutting and sharing the social realism, so as to suit the professional necessities of respectively of the divisions surrounded by the social sciences, is not very obliging in expansion studies, which, afterward a distance of comparable divisions, is now dreadful out for a more comprehensive and combined viewpoint on some of its own single difficulties [26] But what is of inferior quality, in order to continue their methods, even when they are lengthy to expansion studies, defensibly or then, the advocates of the key body of theoretical knowledge in the social sciences be likely to look down upon everything 'interdisciplinary' as not difficult sufficient, and consequently devoid of intelligent propriety. Such ideas of abstract propriety have often melancholy scholars from observing into the difficulty of growth procedures [7]

Sustainable development means 'growth that encounters the needs of the contemporary without cooperating the aptitude of upcoming group to see their needs' [29, 31]. If we accept that 'human beings are at the Centre for apprehension for sustainable development' [29]. Principle 
1), then the focus of education that is causal to sustainable development develops clear. Education has long been agreed as causal to the growth of human probable as well as social development $[4,12]$. It also has been understood as an elementary human right and as an essential part of admission to political power and contribution for men and women [11] and can, therefore, be careful as an performance of entertaining persons for social capabilities. In particular, in the situation of some questions about the sustainability of development processes, instruction have to causal to the capability of persons to contribute in concept a sustainable way of life.

\section{Public Empathetic of Sustainability}

This description indicates that the Ethiopian primary education is developing in this time. By the increasing of increasing public empathetic of sustainability is creation development near to additional sustainable humanities that necessitates an inhabitants that is aware of the goals of sustainable societies and has the knowledge and skills to contribute toward the objectives. So Ethiopian society got more educated it will be more informed and more knowledgeable about consumers can help communities and governments enact sustainability events and change on the way to extra sustainable societies.

According to $[24,28]$ there are disparities by sub-sector, where the per-student recurrent spending at the university level as of 2012/13 is 26 times that of primary education and 10 times that of secondary education. The same is also true with capital expenditure, where higher education, main universities, accounts for almost 80 percent of the education capital budget." It indicates that education is increasing time to time.

According [12, 15], has observed Ethiopia's human development tendencies observing explicitly at health facilities, education and poverty tendencies. But in the objective of sustainable development, I will focus on education. It is known that education has a great role in improvement. In Ethiopian context, it has been increasing in Ethiopia over the past 15 years, and net registrations in primary school have almost tripled. Since the observing started in 1994. In 201485.7 percentage of Ethiopian primary age children are appearing primary school. Secondary school admission has risen too, but leftovers at fairly low levels, particularly in rural zones and between the lowliest collections. Only in the last five years did the gender gap start lessening at this level of education.

The challenge of refining educational quality in Ethiopia, parallel to other states, has been an issue for decades. In 1990, the World Declaration on Education for All stated that, "the current provision of education is seriously deficient and that it must be made more relevant and qualitatively improved, and made universally available" [33]. Acknowledging that, general, the existing delivery of education on is extremely lacking and that it necessity be completed additional applicable and qualitatively better, and made universally obtainable

ESD recommends that a standard shift in education by stressing and encouraging procedures like serious rational, problem-solving, increasing an all-inclusive vision, arrangements thoughtful and future-oriented thoughtful. Educational institutions as spreaders of cultural standards and, thus, as crucial fundamentals in endorsing cultural modification for sustainable development. Different nations in the glob have ongoing investigation programs in order to classify the most effectual influences to inspiration and carry around cultural change meant to make democracy more valid. Related to these look the next paragraphs in the Ethiopian context.

According to $[6,16]$ in the twentieth century, Ethiopia was one of the countries in the world with actual low employment proportions in education. Though, the new regime modification in the primary 1990s, education appropriated a located at the center of Ethiopia's growth policy and calculated constitutionally in such a way that every inhabitant has the right to equivalent contact to instruction, and that is free from spiritual inspiration, radical bias or cultural prejudices $[22,28]$

According to $[20,22,26]$ one current modification in the higher education system is related through the proportion of university assignment by estates of specialization, where supplementary importance is assumed to science and technology (S\&T) over social sciences and humanities (SHS). To be able to produce skilled citizens well-equipped with skills favorite for Ethiopia's growth, the government of Ethiopia has newly made a significant change to the ratio of students studying under the two streams. The share of S\&T to SHS changed from $58: 42$ in $2008 / 09$ to $70: 30$ in $2014 / 15$

\section{Conclusions}

Education in Ethiopia: Strengthening the Foundation for Sustainable Progress is part of the World Bank Country Study series. These reports are available to interconnect the consequences of the Bank's work on the economic and connected circumstances of affiliate republics to administrations and to the growth community. According to The $[8,19]$, specify that with the conclusion of civil war in 1991, Ethiopia's government threw a New Education and Training Policy in 1994 which, by the early 2000s, had previously shaped extraordinary consequences. The uncultured registration ratio rose from 20 to 62 percent in primary education between 1993-94 and 2001-02; and in secondary and higher education it augmented from 8 to 12 percent and from 0.5 to 1.7 percent, respectively.

In the Ethiopian context, education gave an essential and improper for all human development and its accessibility and quality are dominant to the human resource development of any civilization. Education for sustainable development takes ground-breaking inspiration for education as pupils developed authorized to develop and evaluate alternative visions of a sustainable future and to work to collect. 
According to [2, 27]. Ethiopian higher education had the problematic of quality of education. Student registration in higher education is nowadays on the growth as linked to the earlier. But the admission amount in the nations of higher education is as small as it has been piercing out is slightly worrying. The nation's growth necessity display palpable consequences, the arithmetical scope of the cultivated manpower should be paralleled by the quantity of ingredient in its information and the degree of its expert competence. And for this to occur, the education providing should be qualitatively advanced, which, in turn, income that the contributions required for the safeguarding of the wanted education for progress [16].

\section{References}

[1] Ashcroft, K. and Rayner, P. (2011), Higher Education in Development. Lessons from Sub-Saharan Africa, Information Age Publishing, Charlotte, NC.

[2] Aweke Shishigu. (2015). Foundation of Curriculum in Ethiopia: Historical, A paper presented in the 33rd May Annual International Educational (pp. 1-20). Bahir Dar: file://E:/dvel.\%20educ/david/tom/New\%20folder/final/ED55 7354.pdf.

[3] Ayalew, S. A. (2013), "Financing higher education in Ethiopia. Analysis of cost-sharing policy and its implication", Higher Education Policy, Vol. 26 No. 1, pp. 109-126.

[4] Bagoly-SimÛ, P. (2014). Tracing sustainability: Education for sustainable development in the lower secondary geography curricula of Germany, Romania, and Mexico. International Research in Geographical and Environmental Education, 23 (2), 126ñ141.

[5] Bates, Robert (2001). Prosperity and Violence: The Political Economy of Development. New Cambridge University Press.

[6] Bishaw, A. (2012, 05). Education in Ethiopia: Past, Present and Future Prospects. African Nebula, 2 (5), 53-69.

[7] Cosette Marie Armstrong (2011); Implementing Education for Sustainable Development: The Potential use of Time-Honored Pedagogical Practice from the Progressive Era of Education; Journal of Sustainability Education Vol. 2, March 2011 ISSN: 2151-7452.

[8] Delors, Jacques (1996) Report to UNESCO on Education for the 21st Century -Learning: A treasure within, Paris: UNESCO.

[9] Deprived Children and Education Ethiopia Heike Roschanski December 2007 Copyright: IREWOC 2007 IREWOC, Cruquiusweg 68-70, 1019 AH Amsterdam, The Netherland.

[10] Educational Inequalities Among Children and Young People in Ethiopia Tassew Woldehanna and Mesele Araya (C) Young Lives 2016 ISBN 978-1-909403-81-9 Young Lives, Oxford Department of International Development (ODID), University of Oxford, Queen Elizabeth House, 3 Mansfield Road, Oxford OX1 3TB, UK.

[11] ERQA (2007). Addis Ababa University Institutional Quality Audit Report. Addis Ababa: National Printing Press PLC.
[12] Exploring education for sustainable development: Its theory and practice in Philippine higher education institutions Bernardino, Caridad S. University of Alberta (Canada), ProQuest Dissertations Publishing, 2000. NQ59564.

[13] Federal Democratic Republic of Ethiopia (FDRE) (1994) Education and Training Policy, Addis Ababa: St. George Printing Press.

[14] Inter-Agency Support Group on Indigenous Peoples' Issues Thematic Paper towards the Preparation of the 2014 World Conference on Indigenous Peoples. Education and Indigenous Peoples: Priorities For Inclusive Education.

[15] M. Mahruf C. Shohel and Andrew J. Howes (2011) Models of Education for Sustainable Development and Non formal Education: A Bangladeshi Perspective; Forthcoming: Journal of Education for Sustainable Development, 5 (1).

[16] Ministry of Education (1994). Education and Training Policy, Transitional Government of Ethiopia, Addis Ababa, Ethiopia.

[17] Ministry of Education (2008). When Things Fell Apart: State Failure in Late-Century Africa. Cambridge.

[18] Ministry of Education (2017.) Education Statistics Annual Abstract 2009 E.C. (2016/17), Addis Ababa, Ethiopia.

[19] Molla, T. (2013), "Higher education policy reform in Ethiopia: the representation of the problem of gender inequality", Higher Education Policy, Vol. 26, pp. 193-215.

[20] Molla, T. (2014), "Knowledge aid as instrument of regulation: World Bank's non-lending higher education support for Ethiopia", Comparative Education, Vol. 50 No. 2, pp. 229248.

[21] National Human Development Report, N. H. (2014). Accelerating Inclusive Growth for. Addis Ababa, Ethiopia: Empowered Lives. Resilient Nations.

[22] Negash, T. (1996). Rethinking Education in Ethiopia. Rethinking Education in Ethiopia. Retrieved from https://escholarship.org/uc/item/1pb0s2qj

[23] Pillay, T. (2010). Critical Perspectives on NGOs and Educational Policy Development in Ethiopia. journal of Alternative Perspectives in the Social Sciences, 92-121.

[24] Prospects, Challenges and policy options of Ethiopian Educational System towards the Achievement of EFA Goals

[25] Tam, M. (2001). Measuring quality and performance in higher education. Quality in Higher Education, 7 (1), 47-54.

[26] Tassew Woldehanna and Mesele Araya (2016) Educational Inequalities Among Children and Young People in Ethiopia; Young Lives, Oxford Department of International Development (ODID), University of Oxford, Queen Elizabeth House, 3 Mansfield Road, Oxford OX1 3TB, UK.

[27] Tefera Tadesse (20 14) Quality Assurance in Ethiopian Higher Education: Boon or Bandwagon in Light of Quality Improvement?; JHEA/RESA Vol. 12, No. 2, 2014, pp. 131157 (C) Council for the Development of Social Science Research in Africa 2015 (ISSN 0851-7762).

[28] Tirussew Teferra, Amare Asgedom, Jeilu Oumer, Tassew W/hanna, Aklilu Dalelo and Berhannu Assefa (2018); Ministry of Education Education Strategy Center (ESC) Draft for Discussion; Ethiopian Education Development Roadmap (2018-30) An integrated Executive Summary; Addis Ababa. 
[29] UNCED (United Nation Conference on the Environment and Development). 1992. Agenda 21: Programmed of Action for Sustainable Development. New York: United Nations Department of Public Information.

[30] UNESCO (2005a) Technical Paper 1: Links between the global initiatives in education, Paris: UNESCO.

[31] UNESCO (2005b) United Nations Decade of Education for Sustainable Development 2005-2014 International Implementation Scheme, Paris: UNESCO.

[32] UNESCO (2008) Education for Sustainable Development Policy Dialogue 1: EFA-ESD dialogue: Educating for a sustainable world, Paris: UNESCO.
[33] UNESCO. (2000). World Education Report The Right to Education: towards Education for All through Life. Paris: UNESCO Publishing. York: W. W. Norton.

[34] Yeneayhu, D. (2011). Ethiopian Education Policy Analysis: Using Foucault's Genealogy. Ethiopian Education Policy Analysis, 1-24.

[35] Young Lives Policy Brief (2014) Educational choices in Ethiopia: What determines whether poor children go to school.

[36] Yin, R. K. (2009). Case study research: Design and methods. (4th Ed.) Washington DC: Sage.

[37] Yin, R. K. (2003). Case study research: Design and Methods. (3rd Ed.) Washington DC: Sage. 